\title{
The relationship between anthropogenic dust and population over global semi-arid regions
}

\author{
Xiaodan Guan ${ }^{1}$, Jianping Huang ${ }^{1}$, Yanting Zhang ${ }^{1}$, Yongkun Xie ${ }^{1}$, and Jingjing Liu ${ }^{2}$ \\ ${ }^{1}$ Key Laboratory for Semi-Arid Climate Change of the Ministry of Education, College of Atmospheric Sciences, \\ Lanzhou University, Lanzhou, 730000, China \\ ${ }^{2}$ School of Mechanical and Instrument Engineering, Xi'an University of Technology, Xi' an 710048, China \\ Correspondence to: Jianping Huang (hjp@1zu.edu.cn)
}

Received: 23 November 2015 - Published in Atmos. Chem. Phys. Discuss.: 18 January 2016

Revised: 9 April 2016 - Accepted: 14 April 2016 - Published: 25 April 2016

\begin{abstract}
Although anthropogenic dust has received more attention from the climate research community, its dominant role in the production process is still not identified. In this study, we analysed the relationship between anthropogenic dust and population density/change over global semi-arid regions and found that semi-arid regions are major source regions in producing anthropogenic dust. The results showed that the relationship between anthropogenic dust and population is more obvious in cropland than in other land cover types (crop mosaics, grassland, and urbanized regions) and that the production of anthropogenic dust increases as the population density grows to more than 90 persons $\mathrm{km}^{-2}$. Four selected semi-arid regions, namely East China, India, North America, and North Africa, were used to explore the relationship between anthropogenic dust production and regional population. The most significant relationship between anthropogenic dust and population occurred in an Indian semi-arid region that had a greater portion of cropland, and the high peak of anthropogenic dust probability appeared with 220 persons $\mathrm{km}^{-2}$ of population density and 60 persons $\mathrm{km}^{-2}$ of population change. These results suggest that the influence of population on production of anthropogenic dust in semi-arid regions is obvious in cropland regions. However, the impact does not always have a positive contribution to the production of anthropogenic dust, and overly excessive population will suppress the increase of anthropogenic dust. Moreover, radiative and climate effects of increasing anthropogenic dust need more investigation.
\end{abstract}

\section{Introduction}

It is well known that anthropogenic activities play an important role in drylands' climate change. Salinization, desertification, loss of vegetative cover, loss of biodiversity, and other forms of environmental deterioration are partly caused by anthropogenic activities (Huang et al., 2016a, b). With rapid economic development, more fossil fuels have been consumed, which produced a great deal of greenhouse gases (GHGs) as well as energy (Barnett and O'Neill, 2010). The released GHGs and heat have induced a strong influence on temperature spatial distribution in recent years ( $\mathrm{Li}$ and $\mathrm{Zhao,}$ 2012), especially in developing countries, where the economic policy relies on extensive growth, which favours results, despite lower resource efficiency and energy waste.

Jiang and Hardee (2011) noted that main factors influencing anthropogenic effects on aerosol emission are economic growth, technological change, and population growth, which cannot be easily simulated using numerical models (Zhou et al., 2010). Recently, better understanding about the effects of human activities on dryland expansion in various scenarios has been achieved (Huang et al., 2016b). It appears that higher densities of younger workers are strongly correlated with increased energy use (Liddle, 2004), carbon dioxide emission (Liddle and Lung, 2010; H. Huang et al., 2014), and energy consumption, and the combined production of heat has been released into the atmosphere along with GHGs. Although human activities play an important role in the process of regional climate change, our understanding of their relationship is extremely limited, especially in drylands (Jiang, 2010). 
Huang et al. (2012) showed that drylands are most sensitive to global warming; this warming was induced by dynamical and radiative factors. Guan et al. (2015a) found that the enhanced warming in drylands was a result of radiativeforced temperature, which has a close relationship with aerosol column burden. The aerosol in drylands has an obvious warming effect (Huang et al., 2006a, 2008; Chen et al., 2010; Ye et al., 2012; Jin et al., 2015), and the aerosol has a wide distribution and tends to have a relatively large optical depth (H. Huang et al., 2010; Bi et al., 2011; Liu et al., 2011; Xu and Wang, 2015; Xu et al., 2015), leading to a significant radiative effect in the drylands. According to the results of Tegen and Fung (1995), the existing atmospheric dust load is hard to explain by natural sources alone. The atmospheric dust load that originates from soil and is disturbed by human activities, such as various land-use practices, can increase the overall dust load and in turn affect radiative forcing. Efforts to quantify the relative importance of different types of dust sources and the factors that affect dust emissions are critical for understanding the global dust cycle, as well as historical and possible future changes in dust emission (Okin et al., 2011; Huang et al., 2015). Therefore, studies on different types of aerosols are necessary in the study of radiative effect (J. Huang et al., 2009, 2014; Wang et al., 2010; Yi et al., 2014).

Generally, the aerosols in drylands are divided into two categories: natural and anthropogenic dusts. Anthropogenic dust originates predominantly from agricultural practices (e.g. harvesting, ploughing, and overgrazing) and changes in surface water (e.g. shrinking of the Caspian Sea, the Aral Sea, and Owens Lake), as well as urban (e.g. construction) and industrial practices (e.g. cement production and transport) (Prospero et al., 2002). Over the past few decades, a combination of higher frequency of warmer and dryer winters/springs in semi-arid and semi-wet regions and changes in vegetated land cover due to human activities have likely increased anthropogenic dust emission over different regions (Mahowald and Luo, 2003). Mulitza et al. (2010) studied the development of agriculture in the Sahel, which was associated with a large increase in dust emission and deposition in the region, and they found that dust deposition is related to precipitation in tropical West Africa on the century scale. Due to the importance of anthropogenic dust in climate study, Huang et al. (2015) developed a detection method of anthropogenic dust emission and presented a global distribution of anthropogenic dust aerosol. The current consensus is that up to half of the modern atmospheric dust load originated from anthropogenically disturbed soils (Tegen et al., 2004). Such a great proportion of anthropogenic dust will greatly influence local radiative forcing. Therefore, influence of human activities on production of anthropogenic dust is critical for predicting and estimating the radiative effect of aerosol in regional climate change.

Most of previous results focused on the emission of natural dust aerosol (Z. Huang et al., 2010; Li et al., 2011; Yi et al., 2011, 2012); the study on anthropogenic dust is relatively limited. In this study, the anthropogenic dust over semi-arid regions is identified by CALIPSO data, and its relationship with human activities is investigated. The method used to distinguish anthropogenic dust from the total dust aerosols is based on that of Huang et al. (2015). This paper is organized as follows. Section 2 introduces the data sets used in this study. Section 3 presents the method used to identify the anthropogenic dust aerosols in the semi-arid regions. Section 4 discusses anthropogenic dust emission over global semi-arid regions and its relationship to human activities, including a comparison among four different semi-arid regions. Our major findings, followed by a discussion of the radiative effect of anthropogenic dust on regional climate change in semiarid regions, are given in Sect. 5.

\section{Data}

\subsection{The aridity index (AI) data set}

In this study, we use the AI to classify different types of regions. The $\mathrm{AI}$ is defined as the ratio of annual precipitation to annual potential evapotranspiration, representing the degree of climatic dryness. The AI data set used in this study (Feng and $\mathrm{Fu}, 2013$; Huang et al., 2016b) is based on the Climate Prediction Center (CPC) data sets. Drylands are identified as regions with $\mathrm{AI}$ values less than 0.65 and are further classified into hyper-arid $(\mathrm{AI}<0.05)$, arid $(0.05 \leq \mathrm{AI}<0.2)$, semiarid $(0.2 \leq \mathrm{AI}<0.5)$, and dry sub-humid $(0.5 \leq \mathrm{AI}<0.65)$ types following Middleton and Thomas (1997). Of the four types, hyper-arid regions are the driest, followed by arid, semi-arid, and dry sub-humid regions. The AI data set is provided by Feng and $\mathrm{Fu}$ (2013) and cover the period from 1948 to 2008 , with a spatial resolution of $0.5^{\circ}$ by $0.5^{\circ}$.

\subsection{Population data}

The population data are from the Gridded Population of the World data set, version 3 (GPWv3, http://sedac.ciesin. columbia.edu/data/collection/gpw-v3), which is maintained by the Center for the International Earth Science Information Network (CIESIN) and the Centro Internacional de Agricultura Tropical (CIAT). GPWv3 depicts global population distribution. It is a gridded, or raster, data product that renders global population data at the scale and extent required to illustrate the spatial relationship between human population and global environment. It aims to provide a spatially disaggregated population compatible with data sets from social, economic, and earth science disciplines. The spatial resolution is $0.5^{\circ} \times 0.5^{\circ}$. The population data estimates are for the years of 1990, 1995, 2000, 2005, and 2010. 


\subsection{Dust detection data}

The instrument used to detect anthropogenic dust is the CALIPSO Cloud-Aerosol Lidar with Orthogonal Polarization (CALIOP). CALIOP acquires vertical profiles of elastic backscatter at two wavelengths (532 and $1064 \mathrm{~nm}$ ) and linear depolarization at $532 \mathrm{~nm}$ from a near-nadir viewing geometry for both day and night (Hu et al., 2007a, b, 2009; Liu et al., 2008). The data sets detail the information of Level1 backscatter, depolarization ratio, and colour ratio profiles along with the Level-2 Vertical Feature Mask (VFM) product and the $5 \mathrm{~km}$ aerosol profile product. The CALIPSO algorithm uses volume depolarization ratio $\left(\delta_{\mathrm{V}}\right)$ greater than 0.075 to identify dust (Omar et al., 2009). In the CALIPSO version 3 VFM data, the cloud aerosol discrimination (CAD) algorithm can separate clouds and aerosols based on multidimensional histograms of scattering properties (e.g. intensity and spectral dependence), which is used in the identifying process.

\subsection{Land cover data}

The Collection 5.1 MODIS global land cover type product (MCD12C1) in 2011 is used to identify types of anthropogenic dust sources. It includes 17 different surface vegetation types and was developed based on the data from the International Geosphere-Biosphere Programme (IGBP) (Friedl et al., 2010), with a spatial resolution of $0.05^{\circ} \times 0.05^{\circ}$. It provides the dominant land cover type and the sub-grid frequency distribution of land cover classes. In the present analysis, croplands, grasslands, cropland mosaics, and urban are the land cover types that are considered as sources of anthropogenic dust. In addition, urban environments are also identified based on the data set of Global Rural-Urban Mapping Project (GRUMP) v1 with a spatial resolution of $500 \mathrm{~m}$ (Schneider et al., 2010). GRUMP is a valuable resource both for researchers studying humanenvironment interactions and for users who want to address critical environmental and societal issues. GRUMPv1 consists of eight global data sets, namely population count grids, population density grids, urban settlement points, urbanextent grids, land/geographic unit area grids, national boundaries, national identifier grids, and coastlines. These components allow the GRUMP $\mathrm{v} 1$ to provide a raster representation of urban areas.

\section{Method for detecting anthropogenic dust aerosol}

Recently, Huang et al. (2015) developed a new method of separating natural dust and anthropogenic dust at the global scale using CALIPSO measurements. They defined a schematic framework of dust sources and used vertical and horizontal transport processes as the foundation for their approach to discriminate anthropogenic dust from natural dust in CALIPSO data, which proceeds in a sequence of four steps. The first step is to detect the total dust load (both natural and anthropogenic). The second step is to determine the source region from which the dust originates. The third step is to determine the height of a planetary boundary layer (PBL), and the final step is to determine the proportion of dust, i.e. that subset of the total dust within the PBL.

After the anthropogenic dust was identified by the detection method described above, the anthropogenic dust column burden was calculated as follows. First, we determined dust extinction coefficient from the "atmospheric volume description", which is used to discriminate between aerosols and clouds in the CALIPSO Level-2 aerosol extinction profile products. Then the dust extinction coefficients with the highest confidence levels $(|\mathrm{CAD}| \geq 70)$ (Liu et al., 2008) and quality control flags of $\mathrm{QC}=0$ or $\mathrm{QC}=1$ were selected. The dust optical depth (DOD, $\tau$ ) was calculated by integrating $\mathrm{CAD}$ and QC-filtered extinction coefficient of dust aerosols over the height of the dust layer. After calculating the global total DOD $\left(\tau_{\mathrm{t}}\right)$ and the anthropogenic DOD $\left(\tau_{\mathrm{a}}\right)$ from the CALIPSO profile products between January 2007 and December 2010, the dust column burden $(M)$ was converted from DOD $(\tau)$, which was performed following Ginoux et al. (2001):

$M=\frac{4}{3} \frac{\rho r_{\mathrm{eff}}}{Q_{\mathrm{ext}}} \tau=\frac{1}{\varepsilon} \tau$,

where $r_{\text {eff }}$ is dust effective radius, $\rho$ is dust density, $Q_{\text {ext }}$ is dust extinction efficiency, and $\varepsilon$ is mass extinction efficiency. The formula also referred empirical values from Ginoux et al. (2012) and assume $r_{\text {eff }}=1.2 \mu \mathrm{m}, \rho=2600 \mathrm{~kg} \mathrm{~m}^{-3}$, $Q_{\text {ext }}=2.5$, and $\varepsilon=0.6 \mathrm{~m}^{2} \mathrm{~g}^{-1}$. This method not only modifies the maximum standard technique developed by Jordan et al. (2010), its derived dust column burden also has a correlation coefficient of 0.73 with the ground-based lidar observation at the Semi-Arid Climate and Environment Observatory of Lanzhou University (SACOL) (Huang et al., 2008; Guan et al., 2009; Liu et al., 2014), indicating its effectiveness in detecting anthropogenic dust.

\section{Results}

\subsection{Anthropogenic dust emission over global semi-arid regions}

Figure 1 shows the global distribution of semi-arid regions along with the mean anthropogenic dust column burden from 2007 through 2010, demonstrating the wide spread of anthropogenic dust. Most of the areas with high anthropogenic dust loading are located in the middle to high latitudes of the Northern Hemisphere, such as North China, Mongolia, northern India, central western North America, and Sahel. The highest values are generally distributed throughout East China and India. Note that the Northern Hemisphere has much more anthropogenic dust than the Southern Hemisphere. Therefore, we select four geographical regions that 


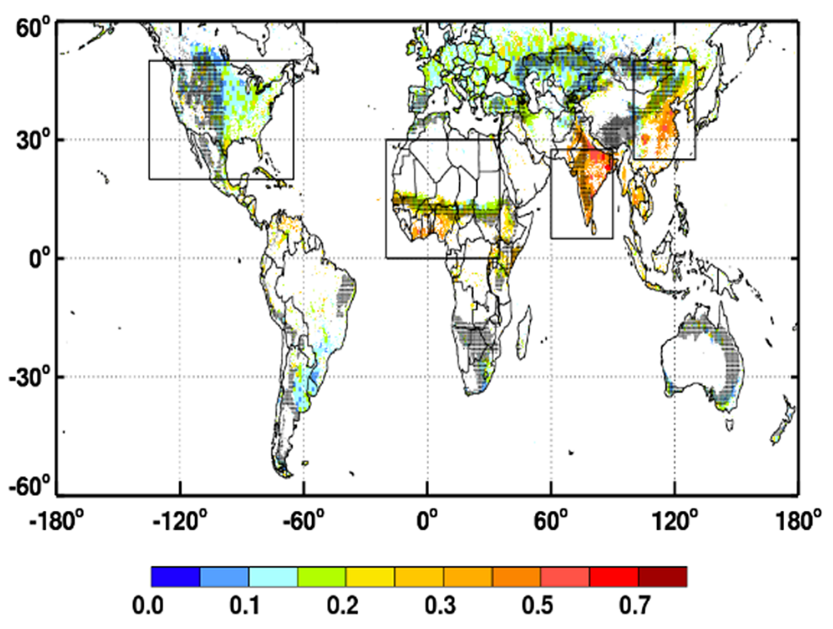

Figure 1. Global distribution of mean anthropogenic dust column burden $\left(\mathrm{g} \mathrm{m}^{-2}\right)$ from 2007 to 2010 . The grey hatching indicates semi-arid regions.

encompass semi-arid regions and are influenced by anthropogenic dust in order to quantify the recent changes. These regions marked in Fig. 1 include East China, India, North America, and North Africa. From a visual inspection of the overlap between the anthropogenic dust distribution and the semi-arid regions, it can be seen that most semi-arid regions coincide with regions of high anthropogenic dust. However, the anthropogenic dust column burdens are different over the selected semi-arid regions: East China and India appear to have greater amounts of anthropogenic dust than North America and North Africa.

Figure 2 displays the total global anthropogenic dust column burden as a function of climatological annual AI during the period of 1948-2004. The mean AI varies from 0.0 to a maximum of 2.0. Note that the intervals in this figure are non-uniform because they are from the classification standard for different types of regions based on the AI, as defined in Sect. 2. Semi-arid region is the transition zone between arid and semi-wet regions; it is defined as the area where precipitation is less than potential evaporation and is characterized by high temperatures $\left(30-45^{\circ} \mathrm{C}\right)$ during the hottest months. According to Huang et al. (2016a), the annual mean precipitation in semi-arid regions ranges from 250 to $500 \mathrm{~mm} \mathrm{yr}^{-1}$ and the $\mathrm{AI}$ of semi-arid region is between 0.2 and 0.5. The global semi-arid regions in Fig. 2 exhibit relatively high peaks in the anthropogenic dust column burden, with AI values ranging between 0.2 and 0.5 . These semi-arid regions also experienced enhanced warming in the period of 1901-2009. (Huang et al., 2012).

Figure 3 compares the anthropogenic dust column burdens in summer (blue), spring (green), autumn (red), and winter (black) as a function of the climatological mean AI. The curves are similar in all four seasons, and the anthropogenic dust column burden exhibits a dominant peak in semi-arid re-

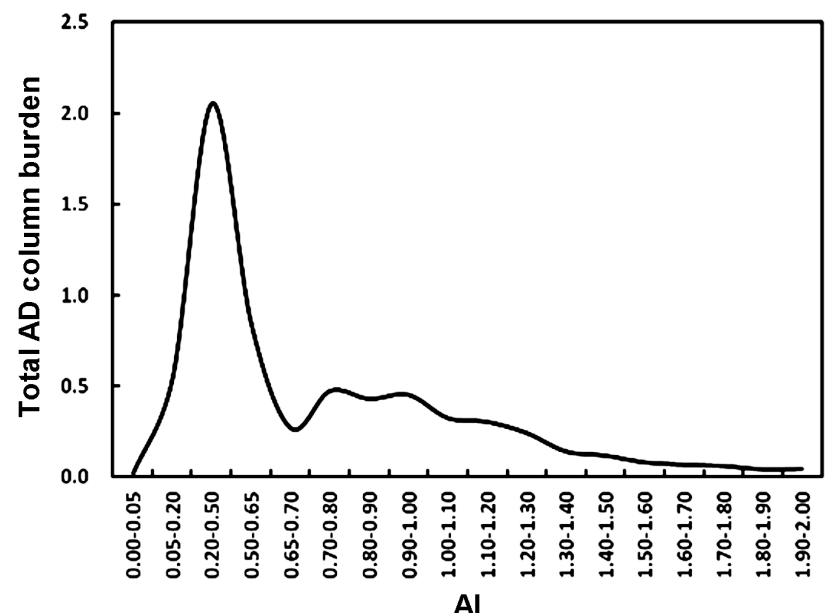

Figure 2. Total global anthropogenic dust (AD) column burden (Tg) as a function of the climatological mean aridity index (AI).

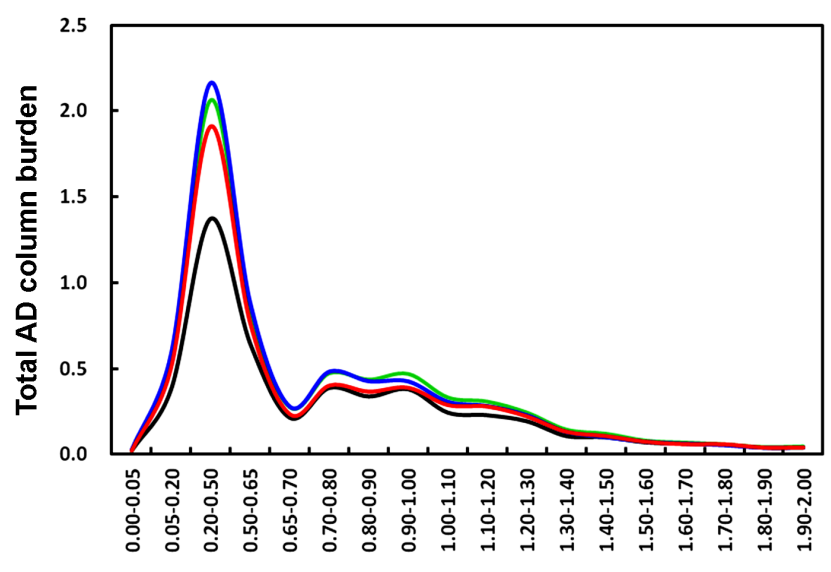

Al

Figure 3. Comparison of the global anthropogenic dust (AD) column burden (Tg) in spring (green), summer (blue), autumn (red), and winter (black) as a function of the climatological mean aridity index (AI).

gions in all four seasons, with values much larger than those in the other regions. For the semi-arid regions, the total anthropogenic dust column burden is the greatest in summer, followed by spring, autumn, and winter, which may relate with the different frequency of human activities (Huang et al., 2015), such as the construction activity is likely to be greater in summer.

In order to illustrate the key role of anthropogenic dust in generating dust aerosols in the semi-arid regions, we compared the dust column burdens corresponding to natural with mixed dust (natural and anthropogenic dusts) in the semiarid regions of the globe, North America, East China, North Africa, and India, in Fig. 4. It is evident that mixed dust aerosol column burden is greater than the pure natural dust of the globe. Both mixed and pure natural dust column burdens 


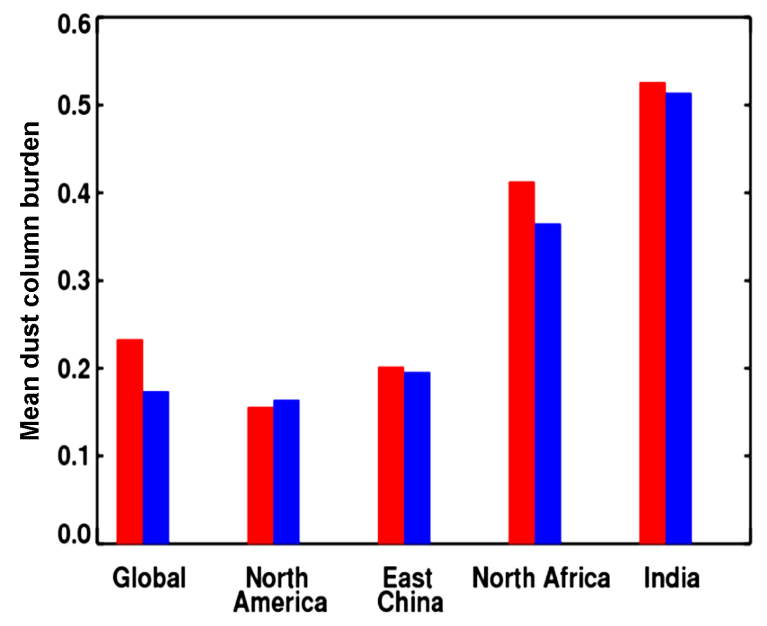

Figure 4. Mean dust column burdens $\left(\mathrm{g} \mathrm{m}^{-2}\right)$ of mixed dust (red) and natural dust (blue) in the global and four geographical semi-arid regions.

are the greatest in India, followed by North Africa and East China. The mixed dust burden of North America is a little less than that of the natural dust. Among these regions where the mixed dust is greater than natural dust, the difference between mixed dust and natural dust is the largest in North Africa, followed by India and East China. For the mixed dust aerosol, the dust column burdens of natural and anthropogenic dusts are presented separately in Fig. 5. It shows that the anthropogenic dust column burden is greater than that of natural dust. Additionally, the highest value of anthropogenic dust column burden is in India, followed by North Africa, East China, and North America; among these regions, the natural dust burden is the highest in North Africa, followed by India, North America, and East China.

Table 1 reports the detailed values of the annual mean anthropogenic and natural dust column burden from mixed dust areas over the semi-arid regions of East China, India, North America, and North Africa. In the semi-arid regions of India, the mean anthropogenic dust column burden is $0.38 \mathrm{~g} \mathrm{~m}^{-2}$ and the natural dust column burden is $0.14 \mathrm{~g} \mathrm{~m}^{-2}$; therefore, the percentage of anthropogenic dust is $73 \%$ of the mixed dust aerosols. The anthropogenic dust values of North Africa, East China, and North America are 0.21, 0.18, and $0.14 \mathrm{~g} \mathrm{~m}^{-2}$ respectively. The natural dust column burdens of North Africa, East China, and North America are 0.20, 0.02, and $0.02 \mathrm{~g} \mathrm{~m}^{-2}$ respectively, whereas the proportions of anthropogenic dust to mixed aerosol in these three regions are 51,90 , and $87.5 \%$ respectively. Therefore, the value of anthropogenic contribution in India is the greatest, much more than the other three selected regions.

\subsection{Population variance in the semi-arid regions}

Figure 6 is the distribution of mean population density. The population density in semi-arid regions exhibits dramatic re-

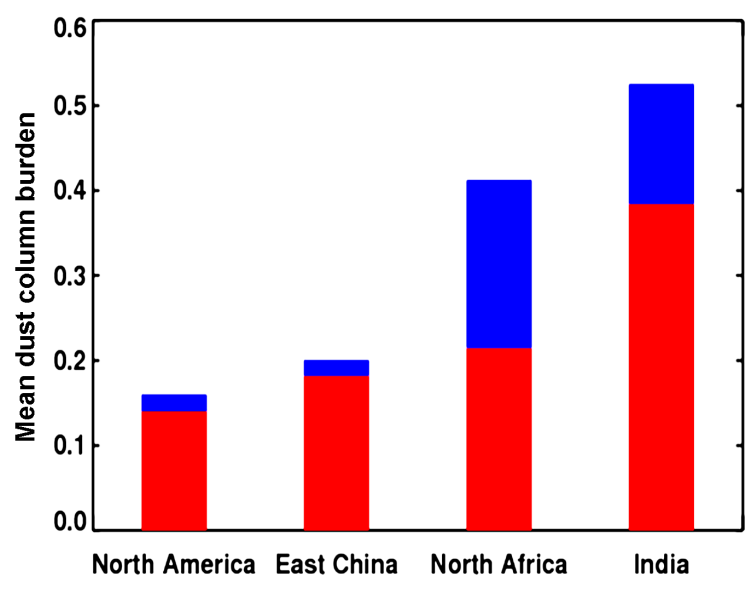

Figure 5. Mean anthropogenic (red) and natural (blue) dust column burdens $\left(\mathrm{g} \mathrm{m}^{-2}\right)$ from mixed dust regions in the four geographical semi-arid regions.

Table 1. Mean dust column burdens $\left(\mathrm{g} \mathrm{m}^{-2}\right)$ in four geographical semi-arid regions.

\begin{tabular}{lrr}
\hline Region & $\begin{array}{r}\text { Anthropogenic } \\
\text { dust }\end{array}$ & $\begin{array}{r}\text { Natural } \\
\text { dust }\end{array}$ \\
\hline East China & 0.18 & 0.02 \\
India & 0.38 & 0.14 \\
North America & 0.14 & 0.02 \\
North Africa & 0.21 & 0.20 \\
\hline
\end{tabular}

gional variability. For the four selected semi-arid regions, both India and East China have higher population densities, most semi-arid regions of North Africa have relatively lower population density, and the population density in the semiarid region of North America is the lowest. The regional difference of population indicates that influences of human activities are not uniformly distributed in the semi-arid areas. Figure 7 illustrates the global distribution of population change between 1990 and 2010. India exhibits the most obvious population change, followed by North Africa and East Asia. North America exhibits an obvious difference between east and west areas, a similar spatial pattern of population change occurred in China. The difference between these respective western and eastern areas may be related to their economic status. The eastern areas of both North America and China are more industrialized than their western counterparts. In a comparison of Figs. 6 and 7, the inconsistent distribution between population density and population change reveals that the regions with the higher population densities do not always have the more obvious population change. Population density and change are related to various factors, such as population policies, economic development status, and political divisions. 


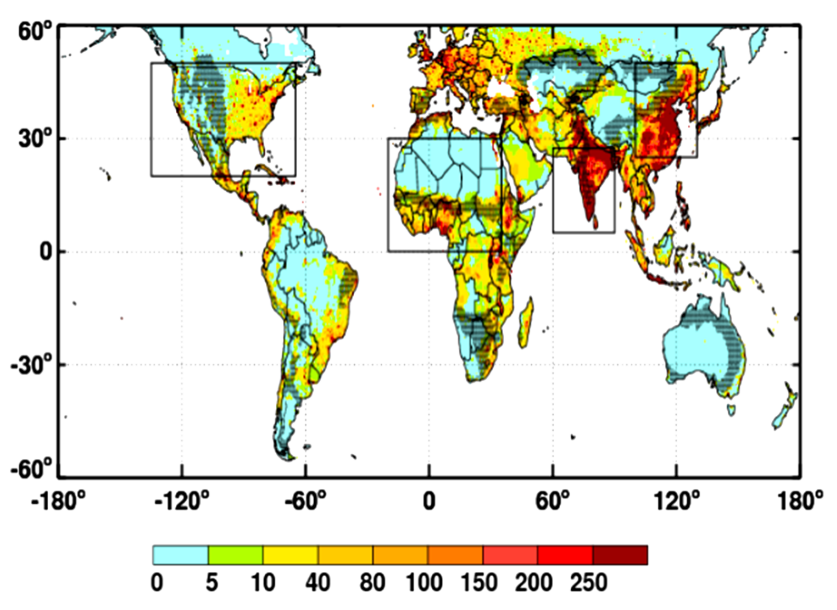

Figure 6. Global distribution of mean population density (persons $\mathrm{km}^{-2}$ ).

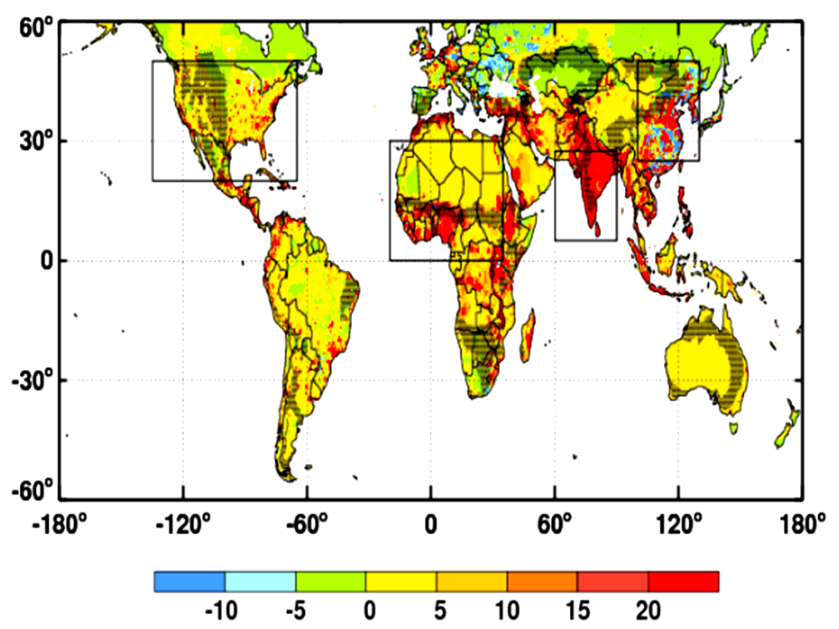

Figure 7. Global distribution of mean population change (persons $\mathrm{km}^{-2}$ ).

Figure 8 compares the mean population density and change in the four selected regions; it is apparent that India has the highest population density, which reaches almost 290 persons $\mathrm{km}^{-2}$. For the other regions, population densities from high to low are North Africa, East China, and North America. Population change appears to be the highest in India as well, followed by North Africa, East China, and North America. More detailed population density and population change are illustrated in Table 2. It shows that India has the highest population density of 290 persons $\mathrm{km}^{-2}$ with a population increase of 80 persons $\mathrm{km}^{-2}$. The second largest population density is North Africa. It has a population of 53 persons $\mathrm{km}^{-2}$, with a population growth of 22 persons $\mathrm{km}^{-2}$. The population densities of East China and North America are 49 and 22 persons $\mathrm{km}^{-2}$ respectively; the population changes in East China and North America are 8 and 6 persons $\mathrm{km}^{-2}$ respectively.

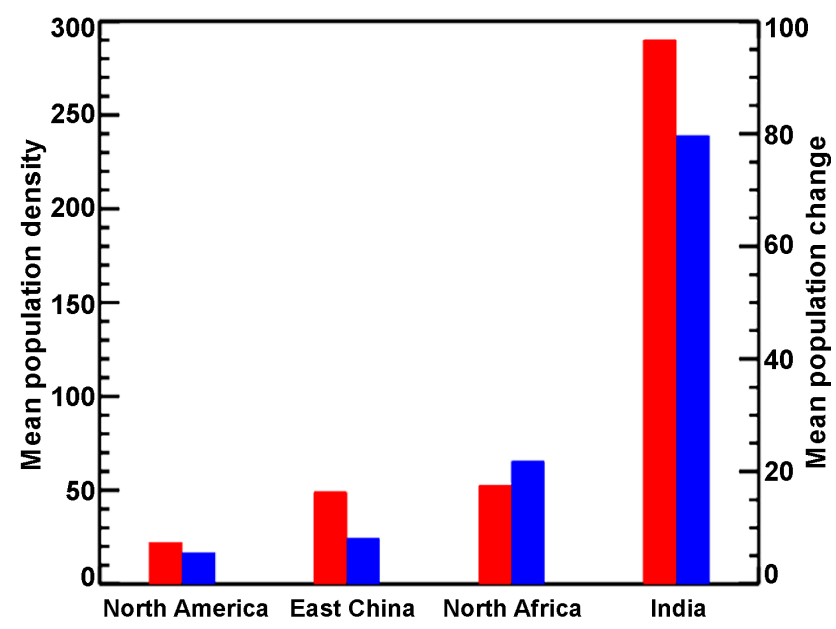

Figure 8. Mean population density (persons $\mathrm{km}^{-2}$ ) (red) and population change (persons $\mathrm{km}^{-2}$ ) (blue) in the four geographical semiarid regions.

Table 2. Mean population density/change (persons $\mathrm{km}^{-2}$ ) in four geographical semi-arid regions.

\begin{tabular}{lrr}
\hline Region & $\begin{array}{r}\text { Mean population } \\
\text { density }\end{array}$ & $\begin{array}{r}\text { Mean population } \\
\text { change }\end{array}$ \\
\hline East China & 49.18 & 8.15 \\
India & 290.07 & 79.69 \\
North America & 22.05 & 5.62 \\
North Africa & 52.73 & 21.85 \\
\hline
\end{tabular}

\subsection{Relationship between anthropogenic dust and population density/change}

Figure 9 is the mean anthropogenic dust column burden as a function of population density. The population varies from 0 to 400 persons $\mathrm{km}^{-2}$ on the $x$ axis with nonuninform intervals, and the mean anthropogenic dust ranges from 0.15 to $0.35 \mathrm{~g} \mathrm{~m}^{-2}$. The anthropogenic dust shows an increase from the population density of greater than 100 persons $\mathrm{km}^{-2}$ and illustrates that high population density greater than 100 persons $\mathrm{km}^{-2}$ has significant effect on anthropogenic dust production. The standard deviation of anthropogenic dust is the highest for population greater than 400 persons $\mathrm{km}^{-2}$ and the lowest for population of 2550 persons $\mathrm{km}^{-2}$. Basically, the standard deviation of anthropogenic dust is larger for high population density. The positive correlation indicates increasing population density may contribute to the production of the anthropogenic dust column burden. Figure 10 is the mean anthropogenic dust as a function of population change. The anthropogenic dust shows obvious increase from the population change that is greater than 25 persons $\mathrm{km}^{-2}$, with a high standard deviation. The positive correlation reveals that the anthropogenic dust increase by population change tends to occur in the case of 


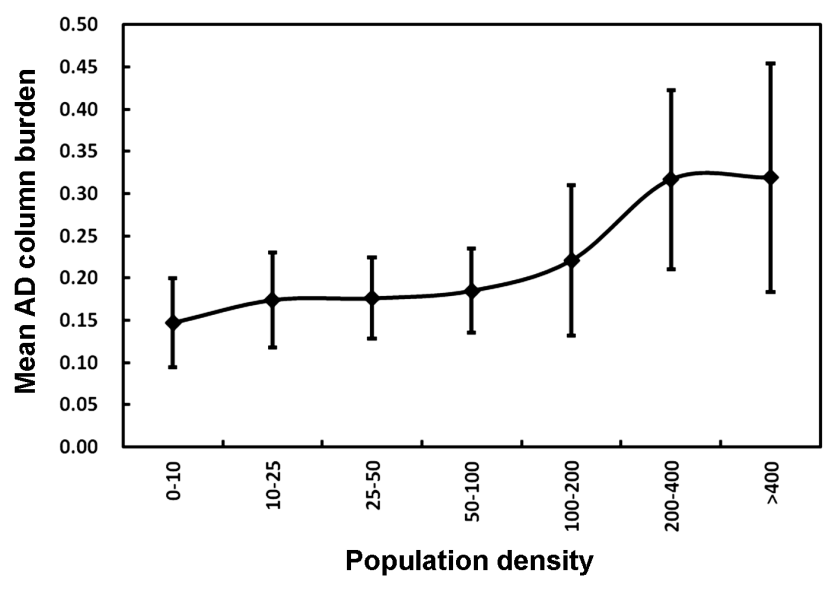

Figure 9. Mean anthropogenic dust (AD) column burden $\left(\mathrm{g} \mathrm{m}^{-2}\right)$ changes as a function of population density (persons $\mathrm{km}^{-2}$ ).

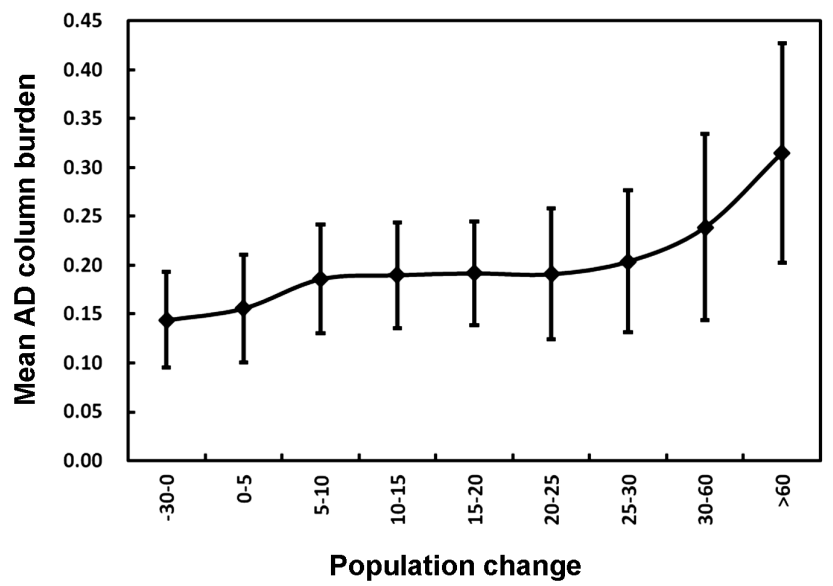

Figure 10. Mean anthropogenic dust (AD) column burden $\left(\mathrm{g} \mathrm{m}^{-2}\right)$ changes as a function of population change (persons $\mathrm{km}^{-2}$ ).

large population change and confirms the positive contribution from high population increase to production of anthropogenic dust in the semi-arid regions.

In the semi-arid regions, four typical land covers in semiarid regions are urban, grassland, cropland, and croplands mosaics. Figure 11 shows the global mean anthropogenic dust column burden in semi-arid region as a function of population density over cropland (blue line), cropland mosaics (which are lands with a mosaic of croplands less than $60 \%$ of the landscape according to Friedl et al., 2002; green line), urban (red line), and grassland (orange line). For population density less than 90 persons $\mathrm{km}^{-2}$, the anthropogenic dust burden over different land covers all shows subtle changes. However, when the population density is larger than 90 persons $\mathrm{km}^{-2}$, the anthropogenic dust exhibits an obvious increase as the population density increases. The anthropogenic dust increases the fastest in the croplands (blue line), followed by crop mosaics, urban, and grassland. Differ-

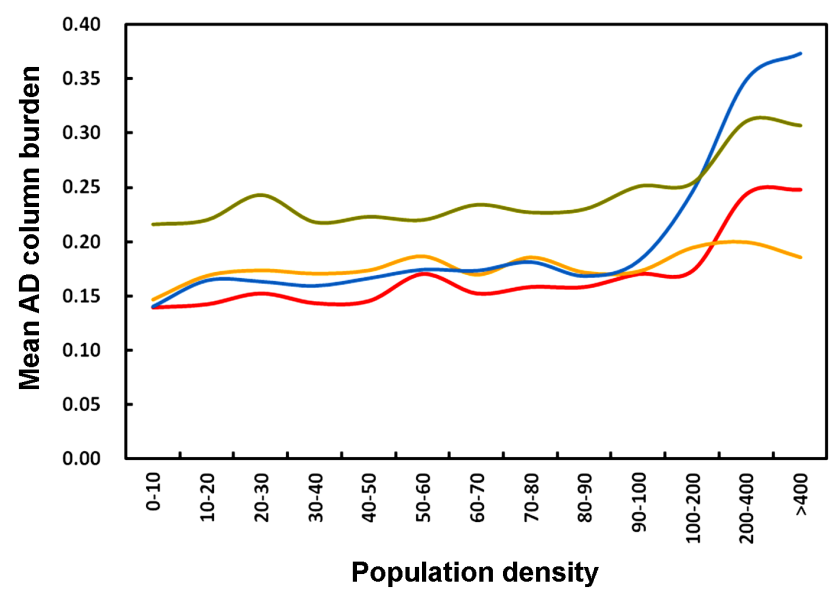

Figure 11. Global mean anthropogenic dust (AD) column burden $\left(\mathrm{g} \mathrm{m}^{-2}\right)$ as a function of population density (persons $\mathrm{km}^{-2}$ ) in semi-arid regions of croplands (blue), croplands mosaics (green), urban (red), and grasslands (orange).

ent variability of anthropogenic dust as a function of population density over different land covers indicates that sensitivities of anthropogenic dust to population are quite different over four typical land covers.

The percentage of different type of land cover in the semiarid regions of East China, India, North America, and North Africa is illustrated in Fig. 12a-d; they show that the components of cropland, grassland, urban, and cropland mosaics are quite different. In the four selected regions, the Indian semi-arid region is dominated by croplands, which has an area of $5.92 \times 10^{5} \mathrm{~km}^{2}$ (Table 3) and takes up $82.85 \%$ of total area (Table 4). The areas of croplands in East China, North America, and North Africa are $0.94 \times 10^{5}, 1.92 \times 10^{5}$, and $2.81 \times 10^{5} \mathrm{~km}^{2}$ respectively and the corresponding percentages of croplands in East China, North America, and North Africa are $6.29,11.51$, and $16.66 \%$ respectively. From both area and percentage, the croplands in India are more than in the other regions. The cropland mosaics have the largest area in North Africa $\left(6.35 \times 10^{5} \mathrm{~km}^{2}\right)$, followed by India $\left(0.73 \times 10^{5} \mathrm{~km}^{2}\right)$, North America $\left(0.13 \times 10^{5} \mathrm{~km}^{2}\right)$, and East China $\left(0.04 \times 10^{5} \mathrm{~km}^{2}\right)$; their percentages are $37.62,10.27$, 0.79 , and $0.29 \%$ respectively. For grassland, it has the largest area in East China $\left(13.67 \times 10^{5} \mathrm{~km}^{2}\right)$, followed by North America $\left(13.51 \times 10^{5} \mathrm{~km}^{2}\right)$, North Africa $\left(7.64 \times 10^{5} \mathrm{~km}^{2}\right)$, and India $\left(0.08 \times 10^{5} \mathrm{~km}^{2}\right)$, with percentages of 91.86 , $80.75,45.22$, and $1.11 \%$ respectively. The urban area is the largest in North America $\left(1.16 \times 10^{5} \mathrm{~km}^{2}\right)$, followed by India $\left(0.41 \times 10^{5} \mathrm{~km}^{2}\right)$, East China $\left(0.23 \times 10^{5} \mathrm{~km}^{2}\right)$, and North Africa $\left(0.08 \times 10^{5} \mathrm{~km}^{2}\right)$, and their percentages are $6.96,5.78,1.56$, and $0.50 \%$ respectively.

Figure 13a-d illustrate the anthropogenic dust probability distributions are quite different in East China, India, North America, and North Africa with intervals of population and dust column burden are 20 persons $\mathrm{km}^{-2}$ and $0.05 \mathrm{~g} \mathrm{~m}^{-2}$. In 
Table 3. Different land cover areas $\left(\mathrm{km}^{2}\right)$.

\begin{tabular}{lrrrr}
\hline Region & Urban area & Grasslands area & Croplands area & Cropland mosaics \\
\hline East China & $0.23 \times 10^{5}$ & $13.67 \times 10^{5}$ & $0.94 \times 10^{5}$ & $0.04 \times 10^{5}$ \\
India & $0.41 \times 10^{5}$ & $0.08 \times 10^{5}$ & $5.92 \times 10^{5}$ & $0.73 \times 10^{5}$ \\
North America & $1.16 \times 10^{5}$ & $13.51 \times 10^{5}$ & $1.92 \times 10^{5}$ & $0.13 \times 10^{5}$ \\
North Africa & $0.08 \times 10^{5}$ & $7.64 \times 10^{5}$ & $2.81 \times 10^{5}$ & $6.35 \times 10^{5}$ \\
\hline
\end{tabular}

Table 4. Different land cover area percentage (\%).

\begin{tabular}{lrrrr}
\hline Region & Urban & Grasslands & Croplands & Cropland mosaics \\
\hline East China & 1.56 & 91.86 & 6.29 & 0.29 \\
India & 5.78 & 1.11 & 82.85 & 10.27 \\
North America & 6.96 & 80.75 & 11.51 & 0.79 \\
North Africa & 0.50 & 45.22 & 16.66 & 37.62 \\
\hline
\end{tabular}

(a) Eas

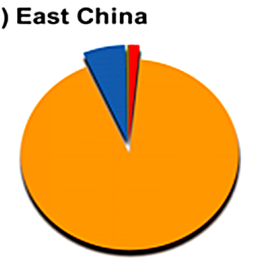

(c) North America

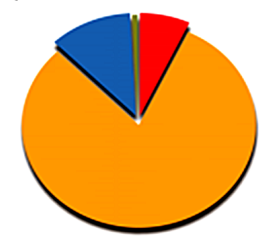

(b) India

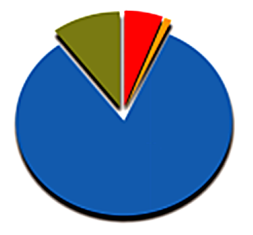

(d) North Africa

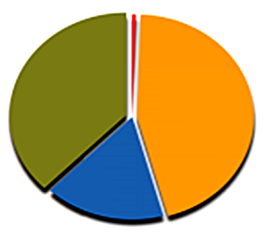

Figure 12. Percentage of different types of land cover in semi-arid regions of East China (a), India (b), North America (c), and North Africa (d).

these different regions, the semi-arid regions in India have the highest anthropogenic dust in the population density of 200-250 persons $\mathrm{km}^{-2}$, and its anthropogenic dust column burden is concentrated around $0.4 \mathrm{~g} \mathrm{~m}^{-2}$. The anthropogenic dust probability in East Asia (Fig. 13a) and North America (Fig. 13c) show that centres of anthropogenic dust are between 0.1 and $0.2 \mathrm{~g} \mathrm{~m}^{-2}$ and the population density is between 0 and 30 persons $\mathrm{km}^{-2}$. Figure $13 \mathrm{~d}$ is the anthropogenic dust in North Africa. The highest anthropogenic dust in North Africa is around 0.2 and $0.3 \mathrm{~g} \mathrm{~m}^{2}$, and the population density concentrated around $0-30$ persons $\mathrm{km}^{-2}$.

The comparison in Fig. 13 highlights the representative relationship between anthropogenic dust and population in India, and Fig. 14 shows that quantified influences of population on anthropogenic dust probability in typical croplands of Indian semi-arid regions with intervals of population density/change are 20 persons $\mathrm{km}^{-2}$. Figure $14 \mathrm{a}$ and $\mathrm{b}$ show nor-
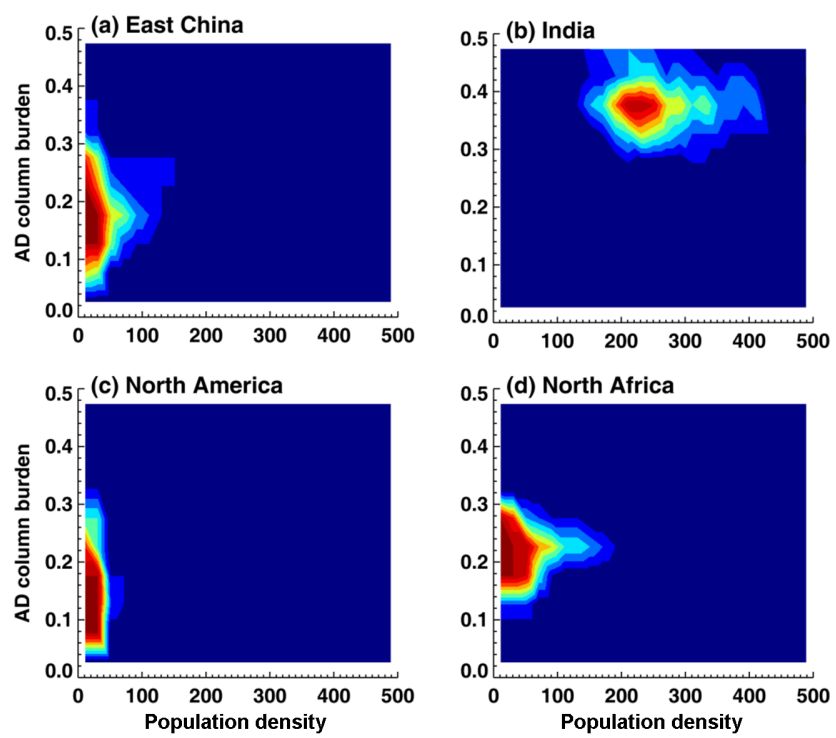

AD probability (\%)

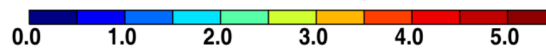

Figure 13. Anthropogenic dust (AD) probability distribution in different population density (persons $\mathrm{km}^{-2}$ ) and $\mathrm{AD}$ column burden $\left(\mathrm{g} \mathrm{m}^{-2}\right)$ value in semi-arid regions of East China (a), India (b), North America (c), and North Africa (d).

mal distribution of anthropogenic dust as a function of population density/change. The population density and population change reach the highest anthropogenic dust probability at the values of 220 and 60 persons $\mathrm{km}^{-2}$ respectively. Figure $14 \mathrm{c}$ and $\mathrm{d}$ show the both the impact from population density and change on anthropogenic dust probability and show that the highest peak of anthropogenic dust probability is located in the population density of 220 persons $\mathrm{km}^{-2}$ and population change of 60 persons $\mathrm{km}^{-2}$. The shape of the 2-D and 3-D figures (Fig. 14c-d) illustrated that the impact from 

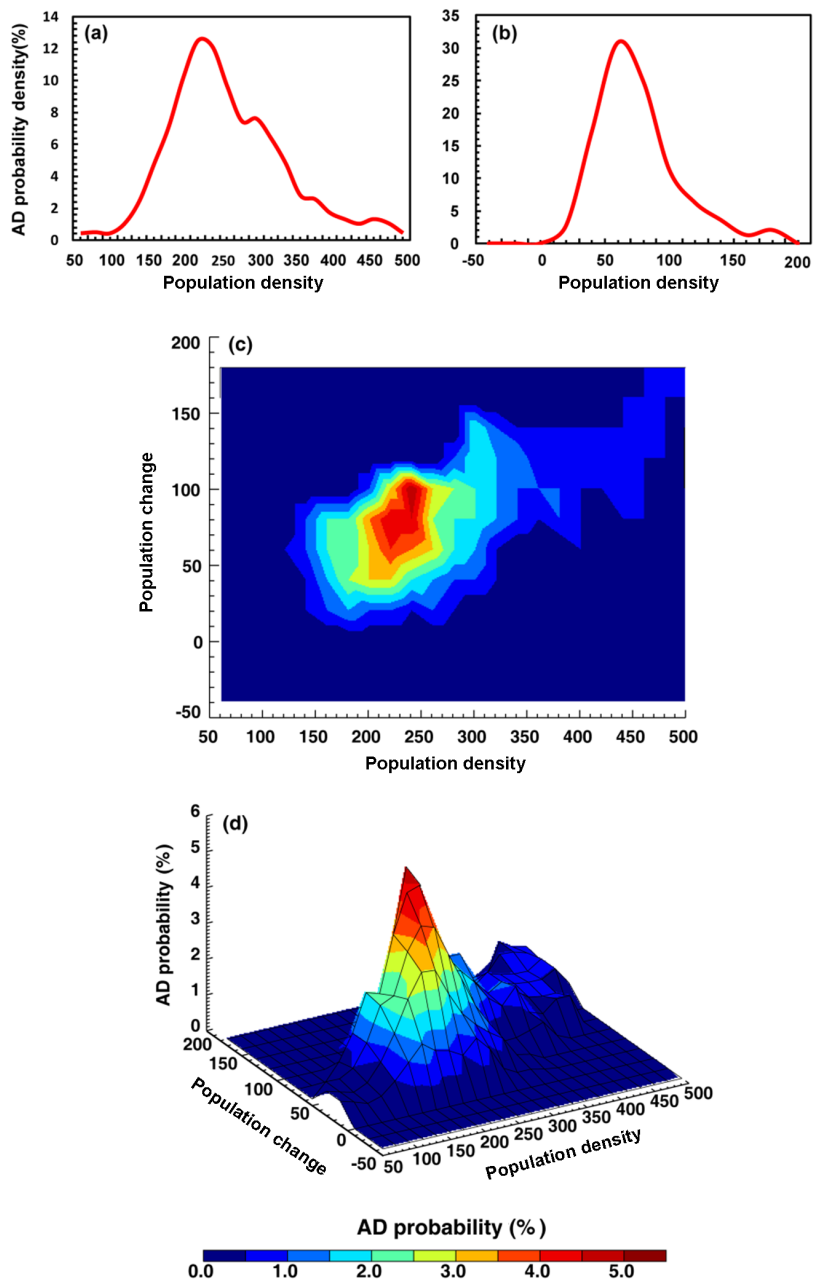

Figure 14. Anthropogenic dust (AD) probability as a function of population density (persons $\mathrm{km}^{-2}$ ) (a), population change (persons $\mathrm{km}^{-2}$ ) (b), 2-D (c), and 3-D (d) of AD probability distribution as a function of population density and change in typical croplanddominated semi-arid regions in India.

population does not always have a positive contribution to the production of anthropogenic dust, and overly excessive population will suppress the increase of anthropogenic dust. Meanwhile, the relationship in croplands of Indian semi-arid regions performs a direct influence of human activities on environment change. Moreover, as the total dust aerosol in India has been greatly increased by anthropogenic dust aerosol, it has changed the radiative effect of dust aerosol and the radiative balance as well. Eventually, it will contribute to regional climate change, if it does not already. Therefore, the relationship shown in Fig. 14 has quantified the influence of human activities on regional climate for croplands in semiarid regions.

\section{Summary and discussion}

In this paper, we focused on the relationship between anthropogenic dust and population. It was found that the total anthropogenic dust column of globe exhibited an obvious peak in the semi-arid regions, which were much higher than it in the other regions. Four geographical semi-arid regions of East China, India, North America, and North Africa were chosen as our study areas according to their anthropogenic dust levels and population. Both population density and population change were correlated with anthropogenic dust, indicating that these population features had effects on the production of anthropogenic dust column burden in these semi-arid regions. In particular, typical croplands in the Indian semi-arid region showed a normal relationship between anthropogenic dust with population density/change; the relationship indicated the influence of human activities on environment can be quantified in the process of climate change. Additionally, it also proposed a typical influence of human activities on anthropogenic dust in cropland.

Dust aerosols exert a key impact on regional radiative forcing over semi-arid regions (Huang et al., 2006b) and are closely related to local climate change (Guan et al., 2015b). Historical statistics revealed that population change occurs in parallel with economic growth and with increases in energy consumption, GHG emission, and anthropogenic dust. Further studies are needed to gain a better understanding of the influence of anthropogenic dust aerosols on climate change in semi-arid regions. Under the current dynamic economic conditions throughout the world, there are still many developing countries in semi-arid regions that are undergoing extensive economic development or are in the process of transforming from an extensive economic mode to an intensive economic model. Developing countries exhibit high rates of population growth, which must be considered when forming economic development strategies. In the developed countries, population change may also result in increased consumption, higher energy demands, and enhanced GHG production. Therefore, further investigations into the influence of human activities on anthropogenic dust aerosol production and the consequent impacts on regional climate change in semi-arid regions are needed, with an emphasis on understanding the feedback between regional climate change and societal development with the intent to apply more reasonable policies in the process of economic development.

Acknowledgements. This work was jointly supported by the National Basic Research Program of China (2012CB955301), the National Science Foundation of China (41305009, 41575006, 41521004, 41175084), the China 111 project (no. B 13045), and the Fundamental Research Funds for the Central Universities (lzujbky-2015-2, lzujbky-2015-ct03).

Edited by: D. Covert 


\section{References}

Barnett, J. and O'Neill, S.: Maladaptation, Global Environ. Chang., 20, 211-213, doi:10.1016/j.gloenvcha.2009.11.004, 2010.

Bi, J., Huang, J., Fu, Q., Wang, X., Shi, J., Zhang, W., Huang, Z., and Zhang, B: Toward characterization of the aerosol optical properties over Loess Plateau of Northwestern China, J. Quant. Spectrosc. Ra., 112, 346-360, doi:10.1029/2009JD013372, 2011.

Chen, B., Huang, J., Minnis, P., Hu, Y., Yi, Y., Liu, Z., Zhang, D., and Wang, X.: Detection of dust aerosol by combining CALIPSO active lidar and passive IIR measurements, Atmos. Chem. Phys., 10, 4241-4251, doi:10.5194/acp-10-4241-2010, 2010.

Feng, S. and Fu, Q.: Expansion of global drylands under a warming climate, Atmos. Chem. Phys., 13, 10081-10094, doi:10.5194/acp-13-10081-2013, 2013.

Friedl, M. A., McIver, D. K., Hodges, J. C. F., Zhang, X. Y., Muchoney, D., Strahler, A. H., Woodcocka, C. E., Gopal, S., Schneider, A., Cooper, A., Baccini, A., Gao, F., and Schaaf, C.: Global land cover mapping from MODIS: algorithms and early results, Remote Sens. Environ., 83, 287-302, doi:10.1016/S00344257(02)00078-0, 2002.

Friedl, M. A., Sulla-Menashe, D., Tan, B., Schneider, A., Ramankutty, N., Sibley, A., and Huang, X.: MODIS Collection 5 global land cover: algorithm refinements and characterization of new datasets, Remote Sens. Environ., 114, 168-182, doi:10.1016/j.rse.2009.08.016, 2010.

Ginoux, P., Chin, M., Tegen, I., Prospero, J. M., Holben, B., Dubovik, O., and Lin, S. J.: Sources and distributions of dust aerosols simulated with the GOCART model, J. Geophys. Res., 106, 20255-20273, doi:10.1029/2000JD000053, 2001.

Ginoux, P., Prospero, J. M., Gill, T. E., Hsu, N. C., and Zhao, M.: Global-scale attribution of anthropogenic and natural dust sources and their emission rates based on MODIS Deep Blue aerosol products, Rev. Geophys., 50, RG3005, doi:10.1029/2012RG000388, 2012.

Guan, X., Huang, J., Guo, N., Bi, J., and Wang, G.: Variability of soil moisture and its relationship with surface albedo and soil thermal parameters over the Loess Plateau, Adv. Atmos. Sci., 26, 692-700, doi:10.1007/s00376-009-8198-0, 2009.

Guan, X., Huang, J., Guo, R., and Lin, P.: The role of dynamically induced variability in the recent warming trend slowdown over the Northern Hemisphere, Scientific Reports, 5, 12669, doi:10.1038/srep12669, 2015a.

Guan, X., Huang, J., Guo, R., Yu, H., Lin, P., and Zhang, Y.: Role of radiatively forced temperature changes in enhanced semi-arid warming in the cold season over east Asia, Atmos. Chem. Phys., 15, 13777-13786, doi:10.5194/acp-15-13777-2015, 2015 b.

Hu, Y., Vaughan, M., Liu, Z., Lin, B., Yang, P., Flittner, D., Hunt, B., Kuehn, R., Huang, J., Wu, D., Rodier, S., Powell, K., Trepte, C., and Winker, D.: The depolarization-attenuated backscatter relation: CALIPSO lidar measurements vs. theory, Opt. Express, 15, 5327-5332, doi:10.1364/OE.15.005327, 2007a.

Hu, Y., Vaughan, M., McClain, C., Behrenfeld, M., Maring, H., Anderson, D., Sun-Mack, S., Flittner, D., Huang, J., Wielicki, B., Minnis, P., Weimer, C., Trepte, C., and Kuehn, R.: Global statistics of liquid water content and effective number concentration of water clouds over ocean derived from combined CALIPSO and MODIS measurements, Atmos. Chem. Phys., 7, 3353-3359, doi:10.5194/acp-7-3353-2007, 2007b.
Hu, Y., Winker, D., Vaughan, M., Lin, B., Omar, A., Trepte, C., Flittner, D., Yang, P., Nasiri, S. L., Baum, B., Sun, W., Liu, Z., Wang, Z., Young, S., Stamnes, K., Huang, J., Kuehn, R., and Holz, R.: CALIPSO/CALIOP Cloud Phase Discrimination Algorithm, J. Atmos. Ocean Tech., 26, 2293-2309, doi:10.1175/2009JTECHA1280.1, 2009.

Huang, H., Thomas, G. E., and Grainger, R. G.: Relationship between wind speed and aerosol optical depth over remote ocean, Atmos. Chem. Phys., 10, 5943-5950, doi:10.5194/acp-10-59432010, 2010.

Huang, H., Wang, J., Hui, D., Miller, D. R., Bhattarai, S., Dennis, S., Smart, D., Sammis, T., and Reddy, K. C.: Nitrous oxide emissions from a commercial cornfield (Zea mays) measured using the eddy covariance technique, Atmos. Chem. Phys., 14, 1283912854, doi:10.5194/acp-14-12839-2014, 2014.

Huang, J., Lin, B., Minnis, P., Wang, T., Wang, X., Hu, Y., Yi, Y., and Ayers, J. R.: Satellite-based assessment of possible dust aerosols semi-direct effect on cloud water path over East Asia, Geophys. Res. Lett., 33, L19802, doi:10.1029/2006GL026561, 2006a.

Huang, J., Minnis, P., Lin, B., Wang, T., Yi, Y., Hu, Y., SunMack, S., and Ayers, K.: Possible influences of Asian dust aerosols on cloud properties and radiative forcing observed from MODIS and CERES, Geophys. Res. Lett., 33, L06824, doi:10.1029/2005GL024724, 2006b.

Huang, J., Zhang, W., Zuo, J., Bi, J., Shi, J., Wang, X., Chang, Z., Huang, Z., Yang, S., Zhang, B., Wang, G., Feng, G., Yuan, J., Zhang, L., Zuo, H., Wang, S., Fu, C., and Chou, J.: An overview of the semi-arid climate and environment research observatory over the Loess Plateau, Adv. Atmos. Sci., 25, 906-921, doi:10.1007/s00376-008-0906-7, 2008.

Huang, J., Fu, Q., Su, J., Tang, Q., Minnis, P., Hu, Y., Yi, Y., and Zhao, Q.: Taklimakan dust aerosol radiative heating derived from CALIPSO observations using the Fu-Liou radiation model with CERES constraints, Atmos. Chem. Phys., 9, 4011-4021, doi:10.5194/acp-9-4011-2009, 2009.

Huang, J., Guan, X., and Ji, F.: Enhanced cold-season warming in semi-arid regions, Atmos. Chem. Phys., 12, 5391-5398, doi:10.5194/acp-12-5391-2012, 2012.

Huang, J., Wang, T., Wang, W., Li, Z., and Yan, H.: Climate effects of dust aerosols over East Asian arid and semiarid regions, J. Geophys. Res.-Atmos., 119, 11398-11416, doi:10.1002/2014JD021796, 2014.

Huang, J. P., Liu, J. J., Chen, B., and Nasiri, S. L.: Detection of anthropogenic dust using CALIPSO lidar measurements, Atmos. Chem. Phys., 15, 11653-11665, doi:10.5194/acp-1511653-2015, 2015.

Huang, J., Ji, M., Xie, Y., Wang, S., He, Y., and Ran, J.: Global semi-arid climate change over last 60 years, Clim. Dynam., 46, 1131-1150, doi:10.1007/s00382-015-2636-8, 2016a.

Huang, J., Yu, H., Guan, X., Wang G., and Guo, R.: Accelerated dryland expansion under climate change, Nat. Clim. Change, 6 , 166-171, doi:10.1038/nclimate2837, 2016b.

Huang, Z., Huang, J., Bi, J., Wang, G., Wang, W., Fu, Q., Li, Z., Tsay, S., and Shi, J.: Dust aerosol vertical structure measurements using three MPL lidars during 2008 China-U.S. joint dust field experiment, J. Geophys. Res., 115, D00K15, doi:10.1029/2009JD013273, 2010. 
Jiang, L.: The impacts of demographic dynamics on climate change, Popul. Res., 34, 59-69, 2010 (in Chinese).

Jiang, L. and Hardee, K.: How do recent population trends matter to climate change?, Popul. Res. Policy. Rev., 30, 287-312, doi:10.1007/s11113-010-9189-7, 2011.

Jin, Q., Wei, J., Yang, Z.-L., Pu, B., and Huang, J.: Consistent response of Indian summer monsoon to Middle East dust in observations and simulations, Atmos. Chem. Phys., 15, 9897-9915, doi:10.5194/acp-15-9897-2015, 2015.

Jordan, N. S., Hoff, R. M., and Bacmeister, J. T.: Validation of Goddard Earth Observing System-version 5 MERRA planetary boundary layer heights using CALIPSO, J. Geophys. Res., 115, D24218, doi:10.1029/2009JD013777, 2010.

Li, Y. and Zhao, X.: An empirical study of the impact of human activity on long-term temperature change in China: A perspective from energy consumption, J. Geophys. Res., 117, 17117, doi:10.1029/2012JD018132, 2012.

Li, Z., Niu, F., Fan, J., Liu, Y., Rosenfeld, D., and Ding, Y.: Long-term impacts of aerosols on the vertical development of clouds and precipitation, Nat. Geosci., 4, 888-894, doi:10.1038/NGEO1313, 2011.

Liddle, B.: Demographic dynamics and per capita environmental impact: using panel regressions and household decomposition to examine population and transport, Popul. Environ., 26, 23-39, doi:10.1023/B:POEN.0000039951.37276.f3, 2004.

Liddle, B. and Lung, S.: Age-structure, urbanization, and climate change in developed countries: revisiting STIRPAT for disaggregated population and consumption-related environmental impacts, Popul. Environ., 31, 317-343, doi:10.1007/s11111-0100101-5, 2010.

Liu, J., Huang, J., Chen, B., Zhou, T., Yan, H., Jin, H., Huang, Z., and Zhang, B.: Comparisons of PBL heights derived from CALIPSO and ECMWF reanalysis data over China, J. Quant. Spectrosc. Ra., 153, 102-112, doi:10.1016/j.jqsrt.2014.10.011, 2014.

Liu, Y., Huang, J., Shi, G., Takamura, T., Khatri, P., Bi, J., Shi, J., Wang, T., Wang, X., and Zhang, B.: Aerosol optical properties and radiative effect determined from sky-radiometer over Loess Plateau of Northwest China, Atmos. Chem. Phys., 11, 1145511463, doi:10.5194/acp-11-11455-2011, 2011.

Liu, Z., Liu, D., Huang, J., Vaughan, M., Uno, I., Sugimoto, N., Kittaka, C., Trepte, C., Wang, Z., Hostetler, C., and Winker, D.: Airborne dust distributions over the Tibetan Plateau and surrounding areas derived from the first year of CALIPSO lidar observations, Atmos. Chem. Phys., 8, 5045-5060, doi:10.5194/acp-85045-2008, 2008.

Mahowald, N. M. and Luo, C.: A less dusty future?, Geophys. Res. Lett., 30, 1903, doi:10.1029/2003GL017880, 2003.

Middleton, N. and Thomas, D. (Eds.): World atlas of desertification, 2nd Edn., UNEP, Edward Arnold, Hodder Headline, London, UK, 1997.

Mulitza, S., Heslop, D., Pittauerova, D., Fischer, H. W., Meyer, I., Stuut, J.-B., Zabel, M., Mollenhauer, G., Collins, J. A., and Kuhnert, H.: Increase in African dust flux at the onset of commercial agriculture in the Sahel region, Nature, 466, 226-228, doi:10.1038/nature09213, 2010.

Okin, G. S., Bullard, J. E., Reynolds, R. L., Ballantine, J. A. C., Schepanski, K., Todd, M. C., Belnap, J., Baddock, M. C., Gill, T. E., and Miller, M. E.: Dust: Small-scale processes with global consequences, Eos, 92, 241-242, doi:10.1029/2011EO290001, 2011.

Omar, A. H., Winker, D. M., Kittaka, C., Vaughan, M. A., Liu, Z., Hu, Y., Trepte, C. R., Rogers, R. R., Ferrare, R. A., and Lee, K. P.: The CALIPSO automated aerosol classification and lidar ratio selection algorithm, J. Atmos. Ocean. Tech., 26, 1994-2014, doi:10.1175/2009JTECHA1231.1, 2009.

Prospero, J. M., Ginoux, P., Torres, O., Nicholson, S. E., and Gill, T. E.: Environmental characterization of global sources of atmospheric soil dust identified with the Nimbus 7 Total Ozone Mapping Spectrometer (TOMS) absorbing aerosol product, Rev. Geophys., 40, 2-1-2-31, doi:10.1029/2000RG000095, 2002.

Schneider, A., Friedl, M. A., and Potere, D.: Mapping global urban areas using MODIS $500 \mathrm{~m}$ data: new methods and datasets based on "urban ecoregions", Remote Sens. Environ., 114, 1733-1746, doi:10.1016/j.rse.2010.03.003, 2010.

Tegen, I. and Fung, I.: Contribution to the atmospheric mineral aerosol load from land surface modification, J. Geophys. Res., 100, 18707-18726, doi:10.1029/95JD02051, 1995.

Tegen, I., Werner, M., Harrison, S., and Kohfeld, K.: Relative importance of climate and land use in determining present and future global soil dust emission, Geophys. Res. Lett., 31, L05105, doi:10.1029/2003GL019216, 2004.

Wang, W., Huang, J., Minnis, P., Hu, Y., Li, J., Huang, Z., Ayers, J., and Wang, T.: Dusty cloud properties and radiative forcing over dust source and downwind regions derived from A-Train data during the Pacific Dust Experiment, J. Geophys. Res., 115, D00H35, doi:10.1029/2010JD014109, 2010.

$\mathrm{Xu}, \mathrm{X}$. and Wang, J.: Retrieval of aerosol microphysical properties from AERONET photopolarimetric measurements: 1. Information content analysis, J. Geophys. Res.-Atmos., 120, 7059-7078, doi:10.1002/2015JD023108, 2015.

Xu, X., Wang, J., Zeng, J., Spurr, R., Liu, X., Dubovik, O., Li, L., Li, Z., Mishchenko, M., Siniuk, A., and Holben, B.: Retrieval of aerosol microphysical properties from AERONET photopolarimetric measurements: 2. A new research algorithm and case demonstration, J. Geophys. Res.-Atmos., 120, 7079-7098, doi:10.1002/2015JD023113, 2015.

Ye, H., Zhang, R., Shi, J., Huang, J., Warren, S. G., and $\mathrm{Fu}, \mathrm{Q}$.: Black carbon in seasonal snow across northern Xinjiang in northwestern China, Environ. Res. Lett., 7, 044002, doi:10.1088/1748-9326/7/4/044002, 2012.

Yi, B., Hsu, C. N., Yang, P., and Tsay, S. C.: Radiative transfer simulation of dust-like aerosols: uncertainties from particle shape and refractive index, J. Aerosol Sci., 42, 631-644, doi:10.1016/j.jaerosci.2011.06.008, 2011.

Yi, B., Yang, P., Bowman, K. P., and Liu, X.: Aerosol-cloudprecipitation relationships from satellite observations and global climate model simulations, J. Appl. Remote Sens., 6, 063503, doi:10.1117/1.JRS.6.063503, 2012.

Yi, B., Yang, P., and Baum, B. A.: Impact of pollution on the optical properties of trans-Pacific East Asian dust from satellite and ground based measurements, J. Geophys. Res.-Atmos., 119, 5397-5409, doi:10.1002/2014JD021721, 2014.

Zhou, L., Dickinson, R. E., Dai, A., and Dirmeyer, P.: Detection and attribution of anthropogenic forcing to diurnal temperature range changes from 1950 to 1999: comparing multi-model simulations with observations, Clim. Dynam., 35, 1289-1307, doi:10.1007/s00382-009-0644-2, 2010. 